\title{
Recovery of Platinum from a Spent Automotive Catalyst through Chloride Leaching and Solvent Extraction
}

\author{
Ana Méndez ${ }^{1}$ (D) Carlos A. Nogueira ${ }^{2}$ and Ana Paula Paiva ${ }^{3, *(D)}$ \\ 1 Departamento de Ingeniería Geológica y Minera, E.T.S.I. Minas y Energía. Universidad Politécnica \\ de Madrid, 28040 Madrid, Spain; anamaria.mendez@upm.es \\ 2 Laboratório Nacional de Energia e Geologia, I. P. (LNEG), Campus do Lumiar, 1649-038 Lisboa, Portugal; \\ carlos.nogueira@lneg.pt \\ 3 Centro de Química Estrutural (CQE), Faculdade de Ciências, Universidade de Lisboa (FCUL), \\ Campo Grande, 1749-016 Lisboa, Portugal \\ * Correspondence: appaiva@ciencias.ulisboa.pt
}

Citation: Méndez, A.; Nogueira, C.A.; Paiva, A.P. Recovery of Platinum from a Spent Automotive Catalyst through Chloride Leaching and Solvent Extraction. Recycling 2021, 6, 27. https://doi.org/10.3390/ recycling 6020027

Academic Editor: Daniel Goldmann

Received: 17 March 2021

Accepted: 15 April 2021

Published: 17 April 2021

Publisher's Note: MDPI stays neutral with regard to jurisdictional claims in published maps and institutional affiliations.

Copyright: (C) 2021 by the authors. Licensee MDPI, Basel, Switzerland. This article is an open access article distributed under the terms and conditions of the Creative Commons Attribution (CC BY) license (https:// creativecommons.org/licenses/by/ $4.0 /)$.

\begin{abstract}
Considering economics and environmental sustainability, recycling of critical metals from end-of-life devices should be a priority. In this work the hydrometallurgical treatment of a spent automotive catalytic converter (SACC) using $\mathrm{HCl}$ with $\mathrm{CaCl}_{2}$ as a leaching medium, and solvent extraction (SX) with a thiodiglycolamide derivative, is reported. The aim was to develop a leaching scheme allowing high $\mathrm{Pt}$ recoveries and minimizing $\mathrm{Al}$ dissolution, facilitating the application of SX. The replacement of part of $\mathrm{HCl}$ by $\mathrm{CaCl}_{2}$ in the leaching step is viable, without compromising $\mathrm{Pt}$ recovery (in the range 75-85\%), as found for the mixture $2 \mathrm{M} \mathrm{CaCl}_{2}+8 \mathrm{M} \mathrm{HCl}$ when compared to 11.6 $\mathrm{M} \mathrm{HCl}$. All leaching media showed good potential to recover $\mathrm{Ce}$, particularly for higher reaction times and temperatures. Regarding SX, results achieved with a model solution were promising, but SX for Pt separation from the real SACC solution did not work as expected. For the adopted experimental conditions, the tested thiodiglycolamide derivative in toluene revealed a very good loading performance for both $\mathrm{Pt}$ and $\mathrm{Fe}$, but Fe removal and Pt stripping from the organic phases after contact with the SACC solution were not successfully accomplished. Hence, the reutilization of the organic solvent needs improvement.
\end{abstract}

Keywords: platinum-group metals (PGMs); cerium; hydrometallurgical recovery; chloride media; liquid-liquid extraction; thiodiglycolamide derivative

\section{Introduction}

The supply of raw materials is essential for the economy of the European Union, as well as for maintaining and improving the quality of life of its citizens. Therefore, in 2011, 2014, 2017 and 2020 [1-4] different critical raw materials (CRMs) lists for the European Union have been published. High amounts of CRMs world production come from a few countries: China, Russia, South Africa, the Democratic Republic of Congo, and Brazil. Additionally, there are low rates of CRMs replacement in their applications, or recycling, in many cases. Among the CRMs there are several metals, such as the so-called rare earths, magnesium, niobium, germanium, gallium, cobalt, tungsten, and platinum group metals (PGMs), mainly, Pd, Pt and Rh [1-4].

PGMs are widely used in the automotive and chemical industries owing to their specific physical and chemical properties. The largest producers of PGMs are South Africa $(61 \%)$ and Russia (27\%). The concentration of these metals in their exploitable ores ranges from $3 \mathrm{~g} / \mathrm{t}$ to $8 \mathrm{~g} / \mathrm{t}$, and they are associated to copper and nickel sulfides [5,6]. PGMs are conventionally recovered from high-grade concentrates, typically containing from 200 to over $2000 \mathrm{~g} / \mathrm{t}$, by the traditional matte-smelting-refining technique, and more recently by hydrometallurgical processes [6], followed by final refining to produce individual $\mathrm{Pt}, \mathrm{Pd}$ or $\mathrm{Rh}$ [7]. It is interesting to note that anodic muds are one important source of PGMs, those 
being produced in the electrolytic refining of base metals. For example, during copper smelting operations gold, silver, and PGMs remain closely associated to copper, firstly within the matte and then within the blister. Finally, during electrorefining of copper blister, PGMs are concentrated and collected in the anode slime [8,9].

Although having several applications in many industrial fields, PGMs main use is as catalysts for the automobile industry [10,11]. $\mathrm{Pt}, \mathrm{Pd}$ and $\mathrm{Rh}$ catalyze reactions in automobile combustion gases, reducing levels of $\mathrm{CO}$, unburnt hydrocarbons, and nitrogen oxides. Stricter control of emissions levels from automobile exhaust gases in several countries is resulting in a greater demand for PGMs. The use of PGMs in electronic components is nevertheless decreasing whereas hydrogen fuel cells with Pt coated electrodes may be an important segment feeding a future growth demand for PGMs [11,12].

Since natural resources for PGMs are limited and their demand from industry is expected to increase, it is important to find effective metallurgical processes for recovery of PGMs from secondary sources, mainly from old automobile catalysts at the end of their useful life [13]. Traditionally, pyrometallurgical processes are the predominant methods employed for the recovery of PGMs from these wastes [14]. Catalysts are commonly added to copper or lead smelting processes, the materials being smelted at temperatures above $1000^{\circ} \mathrm{C}$, and thereafter PGMs are recovered from anode sludges in the subsequent electrorefining processes [14]. However, these industrial processes at extreme temperatures consume high amounts of energy and require important control of atmospheric emissions. In addition, ceramic components of catalysts increase the quantity of slag, which is not valorized; hence, rare earths such as Ce or La cannot be recovered [15]. Furthermore, PGMs in the final anode slime require hydrometallurgical processes for the separation and recovery of individual $\mathrm{Pd}, \mathrm{Pt}$ and $\mathrm{Rh}$ [7]. The sustainable recycling of all materials in the catalysts (ceramics, rare earths and PGMs) with the minimum generation of wastes is necessary to the implementation of circular economy. In addition, the recovery of PGMs and remaining materials needs to be performed by environmentally friendly and economically competitive processes. Accordingly, hydrometallurgical practices could be cleaner and less expensive alternatives to classical pyrometallurgical ones, and hydrometallurgical plants could be implemented at smaller scale than smelter factories [16].

Hydrometallurgical processing involves acid or basic leaching of solids, leading to the dissolution of metals to be recovered. The obtained solutions are then subject to separation procedures such as precipitation of impurities, solvent extraction, adsorption, and ion-exchange to isolate and concentrate the metals of interest. Finally, solutions are treated by electrowinning, crystallization, or chemical reduction for metal production [16]. Hydrometallurgical processing of PGMs employs highly concentrated acid solutions in the presence of oxidizing/chelating agents (for example, aqua regia, mixture of $\mathrm{HNO}_{3}: \mathrm{HCl}$ in a 1:3 ratio) to dissolve $\mathrm{Pt}, \mathrm{Pd}$ and $\mathrm{Rh} . \mathrm{HNO}_{3}$ leads to gaseous compounds like $\mathrm{NOx}$ and fumes during leaching, and its use is considered harmful to the environment [17]. Considering environmental and safety issues, the development of leaching approaches using more environmentally friendly oxidants was necessary. Chloride media allow excellent conditions for PGMs dissolution, and therefore have been widely used in their hydrometallurgical recovery due to some advantages, including a higher leachability of complex metals, stability of chloro-complexes and regeneration of leaching reagents [17-20]. Firstly, the redox potential of the ion/metal pairs strongly decreases in the presence of chloride ions, and secondly, the formation of stable PGMs aquo-chloro-complexes provides stability to oxidized species in aqueous media. Subsequently, ion exchange, precipitation methods and especially solvent extraction (SX) are commonly employed to separate individual PGMs from the leaching solutions [21-23]. PGMs recovery from chloride media is advisable if a convenient and successful SX route is to be designed.

The development of new organic extractants for PGMs separation is mainly focused on model solutions with promising results [22,24]. The main drawback is that the application of those favorable organic extractants to real catalyst waste leaching solutions is still limited but it is nowadays more active [25]. The interactions that may occur between the solvents 
and the other components of the real leaching media, like $\mathrm{Al}$ or $\mathrm{Fe}$, may affect the organic extractants behavior. Therefore, the main objective of this study was to optimize Pt leaching conditions for a spent automobile catalyst, by minimizing the amount of Al extracted, and to test the use of $N, N^{\prime}$-dimethyl- $N, N^{\prime}$-dicyclohexylthiodiglycolamide (DMDCHTDGA) [22,26] to separate $\mathrm{Pt}$ from the optimized leaching solutions obtained. This compound has already been successfully used to recover Pd from an industrial catalyst [20] and its synthetic pathways are quite simple [23], the reagents involved in its production being generally cheap. DMDCHTDGA was obtained as an oily residue with yellowish appearance, without a specific odor, and with a tendency to crystallize over time. It is a stable substance, maintaining its aspect and performance when stored at room temperature, and should be handled adopting the basic procedures advised for manipulation of chemical substances.

\section{Results and Discussion}

\subsection{Catalyst Characterization}

Table 1 shows the results obtained from an initial wavelength dispersive $\mathrm{X}$-ray fluorescence (WDXRF) analysis of the spent automotive catalytic converter (SACC) sample processed in this work.

Table 1. Elemental chemical composition of the SACC sample.

\begin{tabular}{ccc}
\hline Element & Content $(\mathbf{w t} \%)$ & Estimated Error \\
\hline $\mathrm{Si}$ & 20.41 & 0.12 \\
$\mathrm{Al}$ & 18.59 & 0.13 \\
$\mathrm{Mg}$ & 6.69 & 0.09 \\
$\mathrm{Ce}$ & 3.28 & 0.08 \\
$\mathrm{Fe}$ & 0.946 & 0.04 \\
$\mathrm{Ti}$ & 0.516 & 0.026 \\
$\mathrm{~K}$ & 0.489 & 0.024 \\
$\mathrm{P}$ & 0.387 & 0.019 \\
$\mathrm{Pt}$ & 0.257 & 0.013 \\
$\mathrm{Ca}$ & 0.154 & 0.0077 \\
$\mathrm{Na}$ & 0.148 & 0.020 \\
$\mathrm{~Pb}$ & 0.0690 & 0.0065 \\
$\mathrm{La}$ & 0.0662 & 0.0033 \\
$\mathrm{Zn}$ & 0.0560 & 0.0028 \\
$\mathrm{~S}$ & 0.0487 & 0.0024 \\
$\mathrm{Cl}$ & 0.0379 & 0.0041 \\
$\mathrm{Cr}$ & 0.0363 & 0.0019 \\
$\mathrm{Ni}$ & 0.0203 & 0.0012 \\
$\mathrm{Mn}$ & 0.0164 & 0.0016 \\
$\mathrm{Pd}$ & 0.0113 & 0.0022 \\
\hline
\end{tabular}

The most abundant elements were $\mathrm{Si}, \mathrm{Al}$ and $\mathrm{Mg}$, in accordance with the catalyst fabrication process using honeycomb cordierite skeletons $\left(2 \mathrm{MgO} \cdot 2 \mathrm{Al}_{2} \mathrm{O}_{3} \cdot 5 \mathrm{SiO}_{2}\right)$. Cordierite is coated with a highly porous wash-coat composed by approximately $90 \% \gamma-\mathrm{Al}_{2} \mathrm{O}_{3}$ and a mixture of base metals additives, mainly oxides of $\mathrm{Ce}, \mathrm{Zr}, \mathrm{La}, \mathrm{Ni}, \mathrm{Fe}$, and alkaline-earths, in which PGMs are finely dispersed in metallic form $[17,27,28]$. The Ce content was $3.28 \mathrm{wt} \%$, whereas La only represents $0.066 \mathrm{wt} \%$. The presence of these rare earth elements is due to the addition of $\mathrm{Ce}, \mathrm{Zr}$ and La oxides as components of the wash-coat, to improve some properties of the catalysts [28,29]. Ce, $\mathrm{Zr}$ and La oxides promote $\mathrm{Pt}$ dispersion, reducing the particles agglomeration and providing more oxygen vacancy to enhance the catalytic activity [30]. Recent studies have shown that the catalytic performance of PGMs can remarkably improve when $\mathrm{Ce}, \mathrm{La}$ and $\mathrm{Zr}$ are used as electropositive promoters [31].

The Pt content $(0.257 \mathrm{wt} \%)$ was higher than the one reported previously [28]. The amount of Pd was only $0.011 \mathrm{wt} \%$.

The particle size analysis of the ground samples (Figure 1) led to the following characteristic diameters: $d_{10}=85, d_{50}=485$, and $d_{90}=885 \mu \mathrm{m}$, respectively. The sample used 
in the leaching tests comprised all particle size fractions, therefore, being representative of the entire monolith, as this is the supposed situation that best fits industrial practice. Although PGMs contents are expected to be higher in fine fractions (as verified in previous unpublished work), all fractions should be used to avoid PGMs loss.

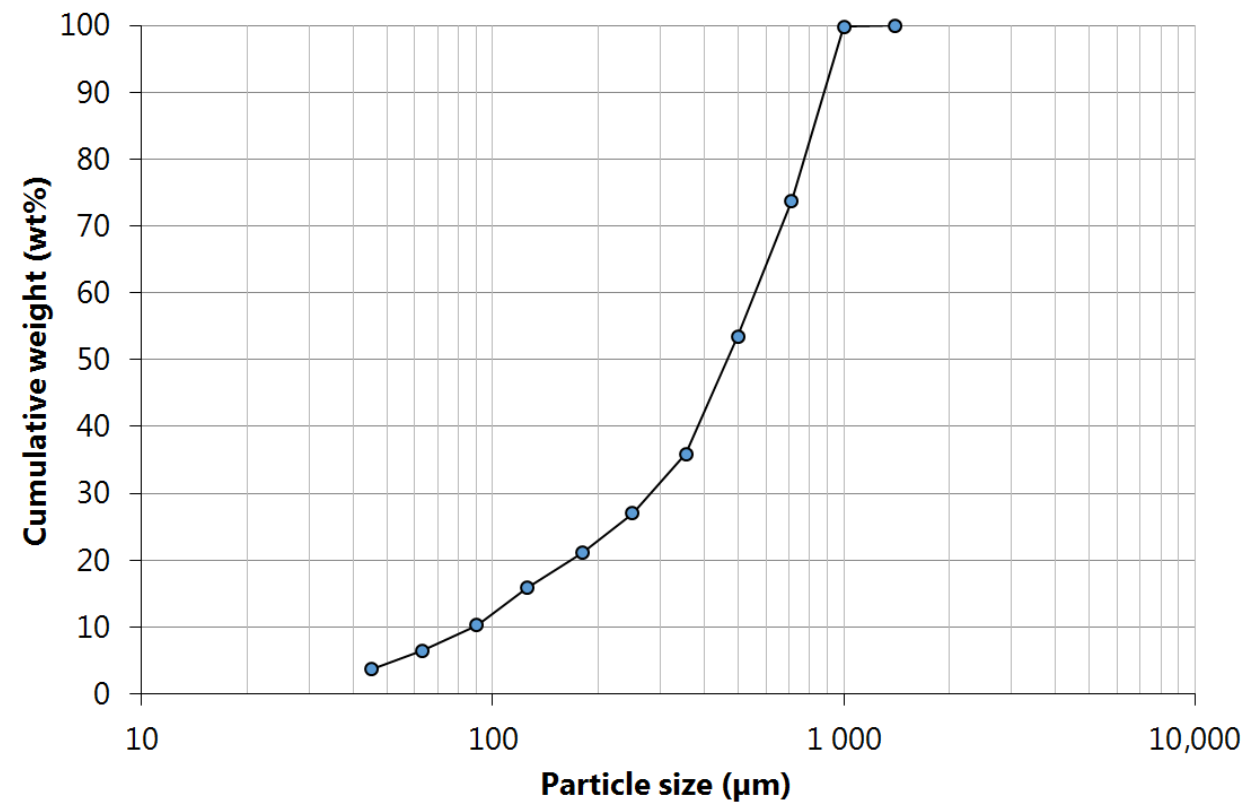

Figure 1. Particle size distribution of the SACC powder sample.

\subsection{Leaching of $\mathrm{Pt}, \mathrm{Ce}$ and $\mathrm{Al}$}

$\mathrm{Pt}$ recovery was the main target of the present work. However, due to the high content of Ce $(\sim 4 \%)$ in the SACC, its possible recovery was also considered. Regarding impurities, $\mathrm{Al}$ should be the most relevant, due to its high content in the catalyst, with a probable negative influence in the subsequent solvent extraction (SX) separation process. Although expecting a low Al leaching yield when considering the general adopted experimental conditions, its high content in the SACC can turn its concentration in the leaching liquor high. Therefore, the first objective was to select leaching conditions for which a better $\mathrm{Pt}$ leaching could be achieved with a lower Al contamination.

PGMs form soluble chloro-complex species in chloride media, hydrochloric acid being the most traditional source of chlorides for leaching. The replacement of a part of hydrochloric acid by another complexing agent, such as a non-volatile chloride salts $\left(\mathrm{AlCl}_{3}\right.$, $\mathrm{NH}_{4} \mathrm{Cl}, \mathrm{MgCl}_{2}$ ) led to successful results according to different research works $[20,32,33]$. For example, Lakshamanan and co-workers [33] proposed that the addition of $\mathrm{MgCl}_{2}$ to $\mathrm{HCl}$ solutions increased the activity of hydrogen ions, helping to improve metal extraction efficiency. Angelidis and Skoraki [32] found that $\mathrm{HCl}$ replacement by $\mathrm{AlCl}_{3}$ did not affect $\mathrm{Pt}$ leaching, whereas the volume of released gases was reduced by $60 \%$. In the current investigation, $\mathrm{HCl}$ replacement by $\mathrm{CaCl}_{2}$ was tested since its high solubility can provide high chloride concentrations in leaching solutions, being simultaneously a relatively low expensive reagent. Moreover, since Al is present in oxide form in the SAAC wash-coat layer, higher acid concentrations would dissolve it more. By substituting $\mathrm{HCl}$ by a soluble chloride salt, and simultaneously using a very high solid/liquid (S/L) ratio $(1 / 2 \mathrm{~kg} / \mathrm{L})$, less $\mathrm{Al}$ concentration in the leachates would be expected, and therefore an improved selectivity towards the PGMs.

The chemical reaction of $\mathrm{Pt}$ leaching in chloride media, with hydrogen peroxide as oxidant precursor, can generally be expressed by Equation (1).

$$
\mathrm{Pt}_{(\mathrm{s})}+4 \mathrm{H}_{(\mathrm{aq})}^{+}+6 \mathrm{Cl}^{-}{ }_{(\mathrm{aq})}+2 \mathrm{H}_{2} \mathrm{O}_{2(\mathrm{aq})} \rightleftharpoons\left[\mathrm{PtCl}_{6}\right]^{2-}{ }_{(\mathrm{aq})}+4 \mathrm{H}_{2} \mathrm{O}_{(\mathrm{aq})}
$$


As a starting point, the use of high $\mathrm{HCl}$ concentrations and simultaneously high S/L ratios (i.e., concentrated pulp densities) would create conditions to decrease the solubility of aluminum chloride in leachates. Accordingly, a concentrated $\mathrm{HCl}$ solution $(\sim 12 \mathrm{M})$ was firstly chosen. Combinations of $\mathrm{HCl}$ with chloride salts, making a total $12 \mathrm{M}$ chloride concentration, were therefore tested. Regarding temperature, values of 60 and $90{ }^{\circ} \mathrm{C}$ were selected, since lower temperatures lead to shorter PGMs recoveries $[19,20]$ and, at the same time, temperatures close to the boiling point of water also cause high aluminum contaminations.

Figure 2 shows the leaching of Pt and Ce at 60 and $90^{\circ} \mathrm{C}$ from the SACC powder using the solutions whose composition is summarized in the Materials and Methods section. Note that solutions $\mathrm{Ca} 2$ and $\mathrm{Ca} 4$ are combinations of $\mathrm{HCl}$ and $\mathrm{CaCl}_{2}$ with constant total chloride concentration $(\sim 12 \mathrm{M})$, while solution D0 was used to evaluate the effect of acid without the presence of salt. $\mathrm{Ca} 0$ did not contain any $\mathrm{CaCl}_{2}$, only $\mathrm{HCl}(\sim 12 \mathrm{M})$ and $\mathrm{H}_{2} \mathrm{O}_{2}$.
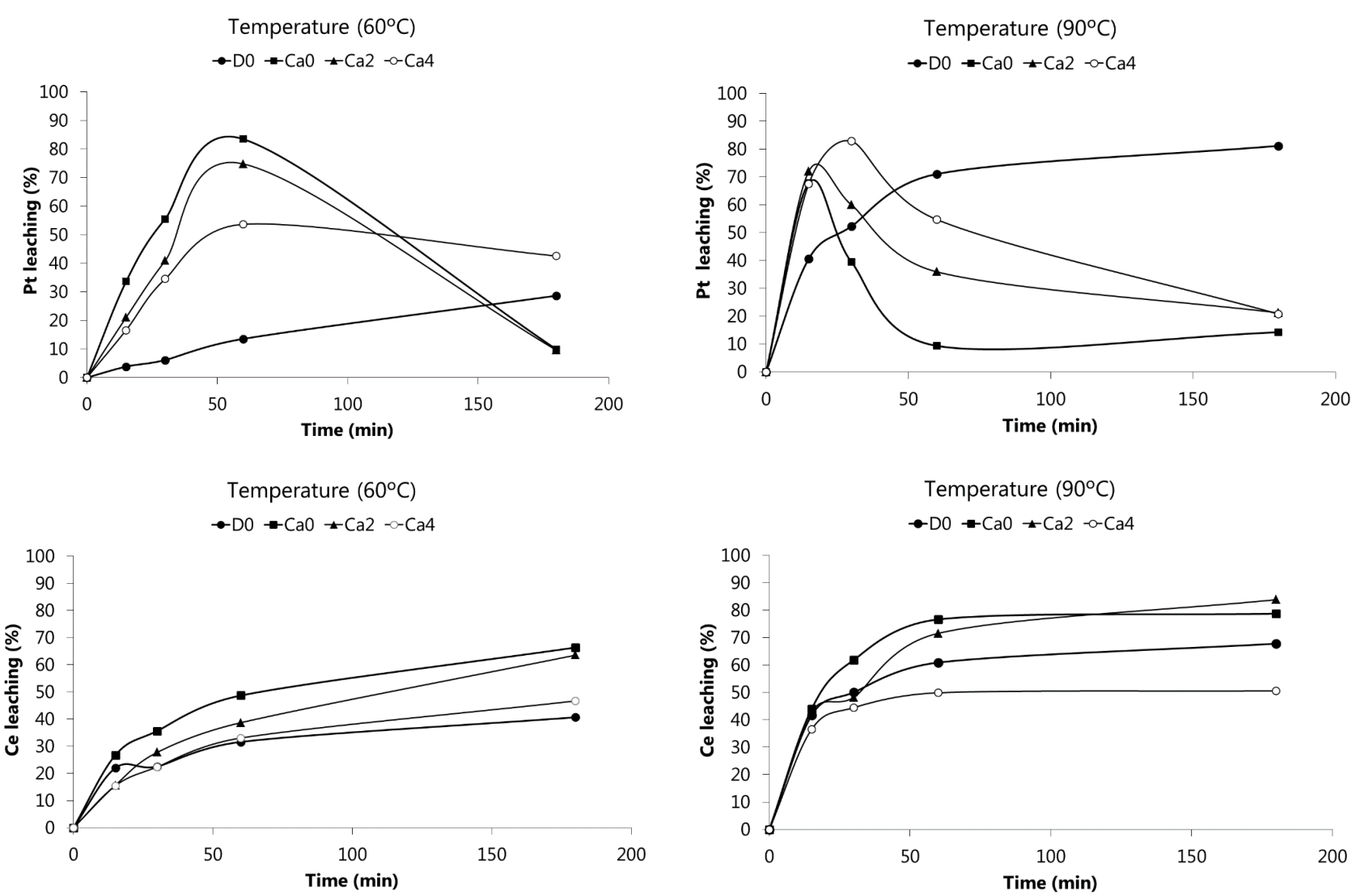

Figure 2. Leaching of $\mathrm{Pt}$ and $\mathrm{Ce}(\mathrm{wt} \%)$ from the SAAC at 60 and $90^{\circ} \mathrm{C}$.

The experimental results obtained showed that the percentage of Pt leaching greatly depend on the leaching solution used, on time and temperature. When $4 \mathrm{M} \mathrm{HCl}$ was used as leaching agent (solution D0, see Materials and Methods), the concentration of $\mathrm{Pt}$ in the leaching liquor increased with time and temperature, with a maximum value of $81 \%$ at $90{ }^{\circ} \mathrm{C}$ after $3 \mathrm{~h}$ of leaching. Leaching solutions with a higher chloride concentration $(\mathrm{Ca} 0$, $\mathrm{Ca} 2$, Ca4) turned Pt leaching faster (yields above $80 \%$ at $30 \mathrm{~min}$ for $\mathrm{Ca} 4$ at $90^{\circ} \mathrm{C}$, or $1 \mathrm{~h}$ for $\mathrm{Ca} 0$ at $60^{\circ} \mathrm{C}$ ). However, after a maximum value leaching, the concentration of $\mathrm{Pt}$ in solution significantly decreased (except for $\mathrm{Ca} 0$ ), probably due to a drop in the electrochemical potential leading to reduction and reprecipitation of Pt. This occurred as the oxidant $\left(\mathrm{H}_{2} \mathrm{O}_{2}\right)$ was consumed by the chemical reactions, and also by decomposition. $\mathrm{H}_{2} \mathrm{O}_{2}$ decomposition helps to explain why the effect was more pronounced at higher temperatures, since the $\mathrm{H}_{2} \mathrm{O}_{2}$ decomposition phenomenon is also faster. 
Concerning $\mathrm{Ce}$, its dissolution at $60^{\circ} \mathrm{C}$ increased over the leaching time. However, at $90{ }^{\circ} \mathrm{C}$, Ce leaching reached maximum values using $\mathrm{Ca} 0$ (79\%) and $\mathrm{Ca} 2$ solutions (84\%). It is worthwhile to mention that leaching of $\mathrm{Ce}$ is also a $\mathrm{H}_{2} \mathrm{O}_{2}$ consumer since this metal is present in the catalyst as $\mathrm{Ce}(\mathrm{IV})$ oxide, requiring a reductant to transform $\mathrm{Ce}(\mathrm{IV})$ into soluble $\mathrm{Ce}(\mathrm{III})$ species. Therefore, $\mathrm{H}_{2} \mathrm{O}_{2}$ may act simultaneously as oxidant and reducer for different metals. These phenomena point out that leaching of SAACs is a quite complex process, involving a series of reactions that can interfere with each other, turning the interpretation of results difficult. It can however be concluded that the leaching of this SACC sample with $\mathrm{Ca} 0$ or $\mathrm{Ca} 2$ solutions made the recovery of $\mathrm{Ce}$ from the wash-coat possible. Cerium is a rare earth element, classified as CRM by the European Community, and it is being increasingly employed as a component of SACCs based on the high prices of PGMs and on its contribution to the improvement of PGMs catalytic properties [15].

Figure 3 shows $\mathrm{Al}$ behavior at 60 and $90^{\circ} \mathrm{C}$ using the leaching solutions summarized in Materials and Methods part. Al leaching significantly increased with time, and specially with temperature. At $90{ }^{\circ} \mathrm{C}$, after $3 \mathrm{~h}$ leaching, the percentage of $\mathrm{Al}$ varied from 16 to $38 \%$. Paiva et al. [20] also observed similar trends.
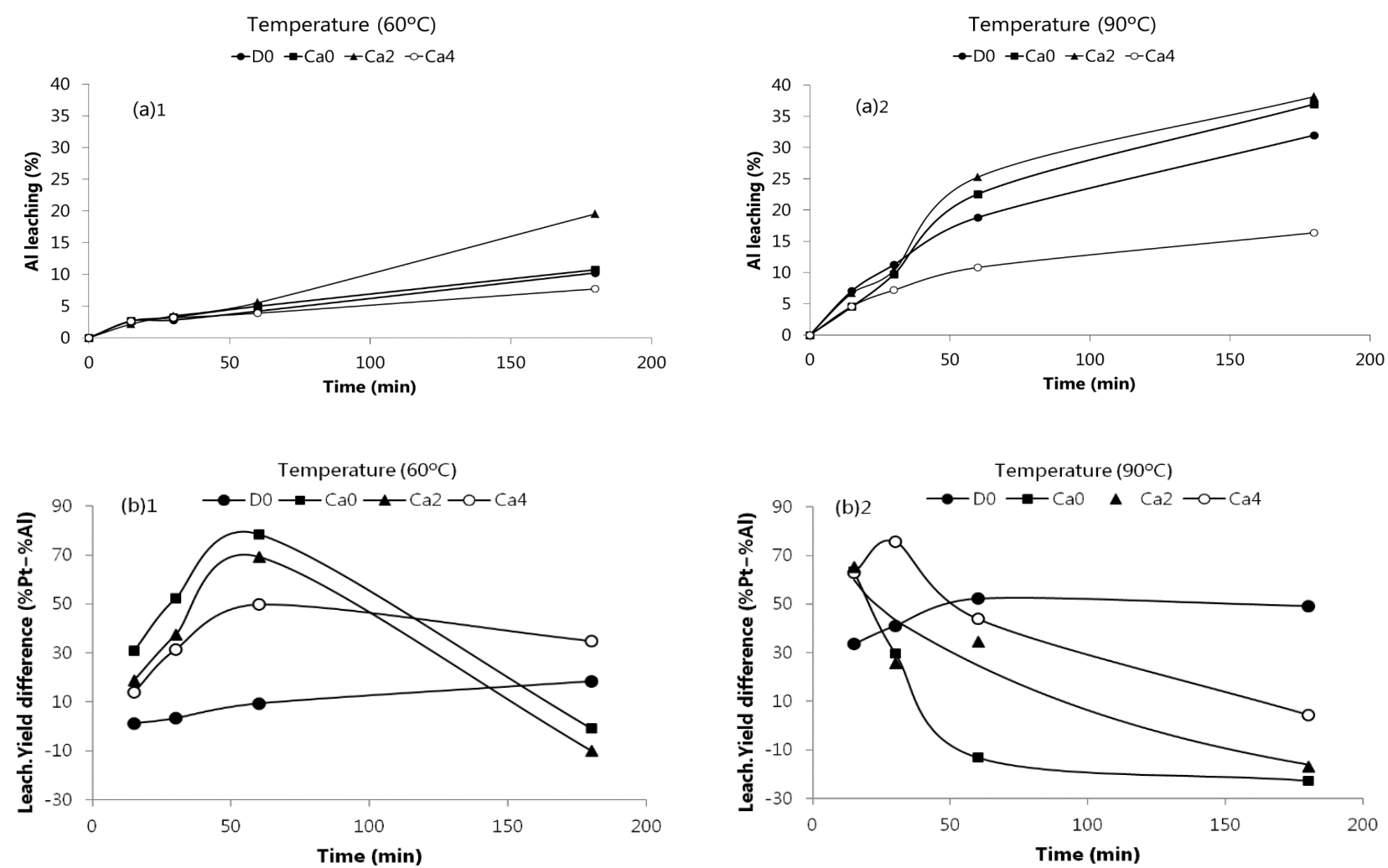

Figure 3. (a) Leaching of $\mathrm{Al}(\mathrm{wt} \%)$ at 60 and $90^{\circ} \mathrm{C}$ from the SACC; (b) Selectivity for $\mathrm{Pt}$ against $\mathrm{Al}$, expressed as leaching yields difference $\% \mathrm{Pt}-\% \mathrm{Al}$.

Comparing Figures 2 and 3, the optimal conditions for an improved leaching of $\mathrm{Pt}$ minimizing $\mathrm{Al}$ dissolution can be realized. At $60^{\circ} \mathrm{C}$ and for $1 \mathrm{~h}$ of reaction time high recoveries of $\mathrm{Pt}$ can be achieved (75-85\%) for the leaching solutions $\mathrm{Ca} 0$ and $\mathrm{Ca} 2$, with only near $5 \% \mathrm{Al}$ dissolution. Alternatively, at $90{ }^{\circ} \mathrm{C}$, similar Pt recoveries can be obtained for 20-30 min, but the dissolved $\mathrm{Al}$ increased up to 7-10\%. The selectivity for Pt against $\mathrm{Al}$ can also be examined by plotting the leaching yields difference between these two metals, as depicted in Figure $3 \mathrm{~b}$, in which the higher selectivity attained at $60^{\circ} \mathrm{C}$ and for a reaction time of $60 \mathrm{~min}$ is shown. Therefore, lower temperatures seem to provide higher selectivity towards Pt. It is also proved that the replacement of part of $\mathrm{HCl}$ by $\mathrm{CaCl}_{2}$, as leachant, is possible, without compromising Pt recovery, as found for the $\mathrm{Ca} 2$ mixture 
(2 $\left.\mathrm{M} \mathrm{CaCl}_{2}+8 \mathrm{M} \mathrm{HCl}\right)$ when compared to $\mathrm{Ca} 0(11.6 \mathrm{M} \mathrm{HCl})$. The former alternative would present some possible advantages, such as the handling of less concentrated acid solutions and decreasing hazards, gaseous emissions, and corrosion effects. Dealing with concentrated $\mathrm{HCl}$ solutions also leads to energy inefficiency due to the volatile character of $\mathrm{HCl}$, consuming latent heat for its evaporation; mixtures of $\mathrm{HCl} / \mathrm{CaCl}_{2}$ can therefore present some benefit in energy consumption, since they are less volatile. Nevertheless, strictly in terms of Pt recovery and $\mathrm{Al}$ co-dissolution, the option of using the mixture of calcium salt/acid did not show advantages as could be expected.

The leach liquor produced under the optimized conditions of $\mathrm{Ca} 0$ and $\mathrm{Ca} 2$ tests allowed the production of leachates with the following composition: $1.1 \mathrm{~g} \mathrm{~L}^{-1} \mathrm{Pt}, 4.6 \mathrm{~g}$ $\mathrm{L}^{-1} \mathrm{Al}$, and $8.0 \mathrm{~g} \mathrm{~L}^{-1} \mathrm{Ce} ; 0.97 \mathrm{~g} \mathrm{~L}^{-1} \mathrm{Pt}, 5.2 \mathrm{~g} \mathrm{~L}^{-1} \mathrm{Al}$ and $6.4 \mathrm{~g} \mathrm{~L}^{-1} \mathrm{Ce}$, respectively. The $\mathrm{Pt}$ concentrations attained were relatively high, considering its low initial content in the catalyst, and this is the reason why the choice of a high pulp density (S/L ratio) was found appropriate. The concentration ratio $\mathrm{Pt} / \mathrm{Al}$ obtained was about $1 / 5$, which seems a good result regarding the selectivity of the leaching operation and considering the very high content of $\mathrm{Al}$ in the catalyst. Other contaminants $(\mathrm{Ca}, \mathrm{Mg}, \mathrm{Fe})$ were also analyzed under these optimized conditions, resulting in the following concentrations: in Ca0 leachate, $0.41 \mathrm{~g} / \mathrm{L} \mathrm{Ca}, 1.70 \mathrm{~g} / \mathrm{L} \mathrm{Mg}$ and $1.37 \mathrm{~g} / \mathrm{L} \mathrm{Fe}$; and in Ca2 leachate, $1.87 \mathrm{~g} / \mathrm{L} \mathrm{Mg}$ and $1.40 \mathrm{~g} / \mathrm{L}$ $\mathrm{Fe}$ (Ca was not analyzed, since in Ca2 calcium is part of the leaching agent).

For the preparation of a batch of real SAAC leachate for the SX experiments, the conditions of $11.6 \mathrm{M} \mathrm{HCl}$ with $1 \% \mathrm{vol} \mathrm{H}_{2} \mathrm{O}_{2}$, at $60^{\circ} \mathrm{C}$ for $1 \mathrm{~h}$ were selected. Hence, an experiment involving $170 \mathrm{~g}$ of SACC and $340 \mathrm{~mL}$ for the optimized leaching solution was then carried out. After filtration, the remaining solution was further diluted with distilled water-see Materials and Methods section.

\subsection{Liquid-Liquid Extraction}

The SX behavior of DMDCHTDGA towards $\mathrm{Pt}(\mathrm{IV})$ recovery from $\mathrm{HCl}$ solutions has been previously evaluated [22,23]. Generally it has been found that $\mathrm{Pt}(\mathrm{IV})$ is efficiently extracted ( $>95 \%$ ) by DMDCHTDGA in 1,2-dichloroethane from $5 \mathrm{M}$ or higher concentrated $\mathrm{HCl}$ aqueous phases, and that water or $1 \mathrm{M} \mathrm{HCl}$ are suitable stripping agents when $\mathrm{Pt}(\mathrm{IV})$ is loaded from concentrated $\mathrm{HCl}$ solutions [23]. This extractant shows nevertheless a higher affinity for Pd(II) than for Pt(IV) [22]. Generally, the selectivity outputs achieved for Pd(II) and $\mathrm{Pt}(\mathrm{IV})$ uptake against $\mathrm{Al}(\mathrm{III})$ are very promising, but $\mathrm{Fe}(\mathrm{III})$ co-extraction is a reality, particularly from the most $\mathrm{HCl}$-concentrated aqueous solutions. Extraction of Fe(III) may not represent a serious drawback though, since its scrubbing from the loaded organic phases can be usually achieved by a simple contact with water [22]. Additionally, although more efficient for $\mathrm{Pd}(\mathrm{II})$ stripping, thiourea in $\mathrm{HCl}$ also works for $\mathrm{Pt}(\mathrm{IV})$ stripping from the DMDCHTDGA solutions [23].

Taking the above results into consideration, the testing of DMDCHTDGA performance when applied to the treatment of real leaching solutions coming from secondary resources [20] was decided. Accordingly, and to find the best conditions to develop a suitable SX methodology to recover Pt effectively and selectively, a model $6 \mathrm{M} \mathrm{HCl}$ aqueous phase containing $\mathrm{Pt}(\mathrm{IV})$ and the most abundant metals in the SACC leaching solution, namely $\mathrm{Fe}(\mathrm{III}), \mathrm{Al}(\mathrm{III})$ and $\mathrm{Ce}(\mathrm{III})$ (having in mind the concentration profiles of those metals in the real SACC leaching solution) was preliminary subject to SX by DMDCHTDGA.

\subsubsection{Model Solution with Pt(IV), $\mathrm{Ce}(\mathrm{III}), \mathrm{Al}(\mathrm{III})$ and Fe(III)}

A series of experiments was planned to check the general SX behavior of DMDCHTDGA towards $\mathrm{Pt}(\mathrm{IV})$ recovery. Hence, a $6 \mathrm{M} \mathrm{HCl}$ feed aqueous solution containing about $500 \mathrm{mg} \mathrm{L}^{-1} \mathrm{Pt}(\mathrm{IV}), 1000 \mathrm{mg} \mathrm{L}^{-1} \mathrm{Fe}(\mathrm{III}), 1000 \mathrm{mg} \mathrm{L}^{-1} \mathrm{Al}(\mathrm{III})$ and $4000 \mathrm{mg} \mathrm{L}^{-1} \mathrm{Ce}(\mathrm{III})$ was extracted by DMDCHTDGA in toluene, and the loaded organic phase was sequentially contacted with distilled water, a $1 \mathrm{M} \mathrm{HCl}$ aqueous phase, and finally with a $0.1 \mathrm{M}$ thiourea in $1 \mathrm{M} \mathrm{HCl}$ solution. The overall results achieved, expressed through the respective extraction, scrubbing, and stripping percentages, are displayed in Table 2. 
Table 2. Extraction, scrubbing, and stripping percentages achieved for the SX process applied to the model solution ${ }^{1}$.

\begin{tabular}{ccccc}
\hline & $\mathbf{P t}(\mathbf{I V})$ & $\mathbf{F e}(\mathrm{III})$ & $\mathbf{A l}(\mathbf{I I I})$ & $\mathbf{C e}(\mathrm{III})$ \\
\hline \% extraction & 98.0 & 99.9 & 0.1 & 1.1 \\
\% scrubbing 1 & 0.2 & 95.2 & traces & traces \\
\% scrubbing 2 & 2.0 & traces & traces & traces \\
\% stripping & 50.5 & traces & traces & traces \\
\hline
\end{tabular}

${ }^{1}$ Feed aqueous phase: $500 \mathrm{mg} \mathrm{L}^{-1} \mathrm{Pt}(\mathrm{IV}), 1000 \mathrm{mg} \mathrm{L}^{-1} \mathrm{Fe}(\mathrm{III})$ and $\mathrm{Al}(\mathrm{III}), 4000 \mathrm{mg} \mathrm{L}^{-1} \mathrm{Ce}(\mathrm{III})$ in $6 \mathrm{M} \mathrm{HCl}$; organic phase: $0.25 \mathrm{M}$ DMDCHTDGA in toluene; scrubbing 1: distilled water; scrubbing 2: $1 \mathrm{M} \mathrm{HCl}$; stripping: $0.1 \mathrm{M}$ thiourea in $1 \mathrm{M} \mathrm{HCl} ; \mathrm{A} / \mathrm{O}=1,30$ min equilibration, $800 \mathrm{rpm}$, room temperature.

Regarding extraction, it can be observed that DMDCHTDGA showed a high affinity for $\mathrm{Pt}(\mathrm{IV})$ uptake, but also for $\mathrm{Fe}(\mathrm{III})$, as expected. On the other hand, $\mathrm{Ce}(\mathrm{III})$ and particularly $\mathrm{Al}(\mathrm{III})$ were not co-extracted. The first scrubbing of the loaded organic phase with water led to the removal of most part of $\mathrm{Fe}(\mathrm{III})$, while $\mathrm{Pt}(\mathrm{IV})$ stayed in the organic phase. Scrubbing with $1 \mathrm{M} \mathrm{HCl}$ caused a slight elimination of $\mathrm{Pt}(\mathrm{IV})$, but not significant. The thiourea solution allowed half recovery of $\mathrm{Pt}(\mathrm{IV})$ from the loaded organic phase. The general composition of the final thiourea aqueous solution contained $230.8 \mathrm{mg} \mathrm{L}^{-1} \mathrm{Pt}(\mathrm{IV}), 9.8 \mathrm{mg} \mathrm{L}^{-1} \mathrm{Fe}(\mathrm{III})$, $0.5 \mathrm{mg} \mathrm{L}^{-1} \mathrm{Al}(\mathrm{III})$ and $0.4 \mathrm{mg} \mathrm{L}^{-1} \mathrm{Ce}(\mathrm{III})$.

The selective scrubbing of the extracted Fe(III) by water is an encouraging result, allowing its effective separation from $\mathrm{Pt}(\mathrm{IV})$, particularly because $\mathrm{Pt}(\mathrm{IV})$ in organic phase remained unaffected. The apparent traceable extraction of $\mathrm{Al}(\mathrm{III})$ and $\mathrm{Ce}$ (III) is also promising, but the incomplete $\mathrm{Pt}(\mathrm{IV})$ stripping by thiourea may compromise a good SX performance, and the finding of alternative stripping agents seems therefore justifiable.

The collected information served as basis for the test of performance of this DMDCHTDGA SX system to recover Pt(IV) from the SACC leaching solution. Hence, experiments to evaluate the loading capability of the organic solution towards $\mathrm{Pt}(\mathrm{IV})$, and also its recyclability potential, were envisaged.

\subsubsection{SACC Leaching Solution}

According to the results obtained from the preliminary experiments, high extractabilities towards Pt and Fe were therefore expected. However, there are much more metallic elements in the SACC leachate apart from the ones considered in the model solution, and that is why analyses of $\mathrm{Mg}$ and Ca were also considered, in addition to those of $\mathrm{Al}$ and Ce.

Considering the dilution factor, the SACC feed solution used for the experiments described in this section had approximately an $8 \mathrm{M} \mathrm{HCl}$ concentration, and the metallic contents were as follows (in mg L ${ }^{-1}$ ): Pt: 512; Fe: 718; Al: 2320; Ce: 3609; Ca: 244; Mg: 816.

Equilibrium extraction isotherms for $\mathrm{Pt}$ and $\mathrm{Fe}$ are depicted in Figure 4, and the data were obtained from the successive loading of the same portion of organic phase containing 0.25 M DMDCHTDGA in toluene with fresh SACC solution, following the experimental conditions described in the Materials and Methods section. The equilibrium metal concentrations in aqueous phase depicted in Figure 4 are those obtained by the successive sum of the remaining metal portions after each extraction. DMDCHTDGA showed a high loading capacity for Pt and especially for Fe, with about 1303 (achieved at the $3^{\text {rd }}$ extraction stage) and $2636 \mathrm{mg} \mathrm{L}^{-1}$, respectively, corresponding to $6.7 \times 10^{-3} \mathrm{M} \mathrm{Pt}$ and $4.7 \times 10^{-2} \mathrm{M} \mathrm{Fe}$. The interference of the remaining metals that were analyzed did not seem notorious, but the analytical errors associated with the most concentrated ones was high, and fluctuations of $\pm 100 \mathrm{mg} \mathrm{L}^{-1}$ and $\pm 200 \mathrm{mg} \mathrm{L}^{-1}$, in relation to the initial contents of $\mathrm{Al}$ and $\mathrm{Ce}$, respectively, were observed. Regarding $\mathrm{Ca}$, the analytical data suggested that vestigial amounts of about $10 \mathrm{mg} \mathrm{L}^{-1}$ seem to be extracted, and sequentially released to the aqueous phase. A similar situation is likely to occur with $\mathrm{Mg}$.

Pt loading by DMDCHTDGA could most likely be enhanced by intermediate scrubbings with water, to remove co-extracted Fe from the organic phase. This assumption has not been tested in these experiments, but water may have the effect of co-removing significant amounts of Pt from the organic phase, as the acidity of the feed SACC is higher 
than in the model solution [23]. Furthermore, recyclability experiments may or not confirm this hypothesis.

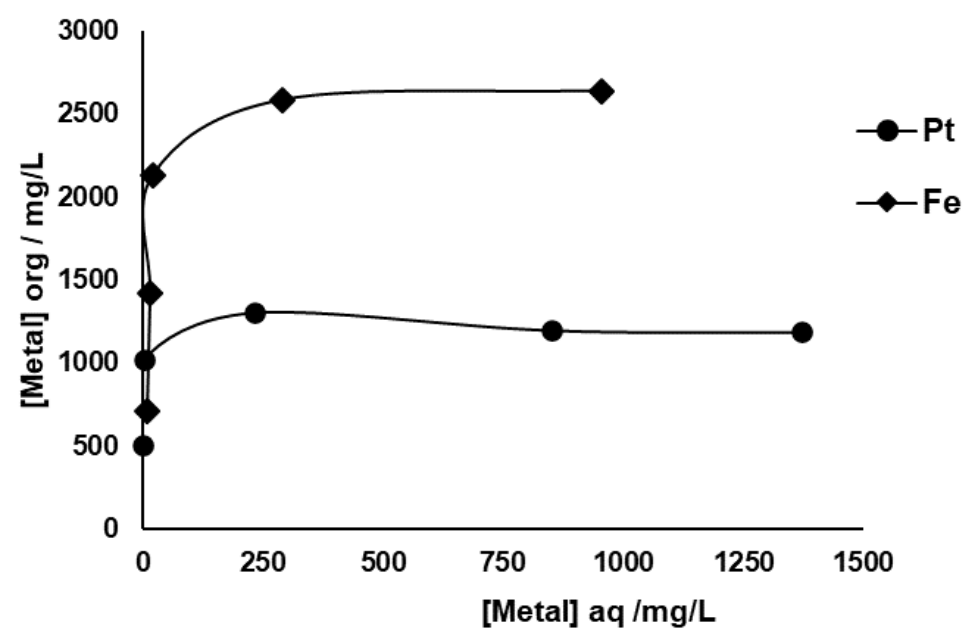

Figure 4. Equilibrium extraction isotherms obtained for 0.25 M DMDCHTDGA in toluene towards Pt and Fe from a SACC leaching solution.

Aliquots of the final loaded organic solution from the equilibrium isotherm experiments were subject to successive contacts with distilled water and $0.1 \mathrm{M}$ thiourea in $1 \mathrm{M}$ $\mathrm{HCl}$ solution (2 contacts each). The results obtained were a bit surprising, although a similar tendency has been previously observed [20]: from $1186 \mathrm{mg} \mathrm{L}^{-1} \mathrm{Pt}$, only about $6 \mathrm{mg} \mathrm{L}^{-1} \mathrm{Pt}$ were removed by the four contacts. The situation was a bit better for Fe: $969 \mathrm{mg} \mathrm{L}^{-1}$ (from $2636 \mathrm{mg} \mathrm{L}^{-1}$ ) were caught up by the sum of the four solutions, the first contact with water removing $926 \mathrm{mg} \mathrm{L}^{-1} \mathrm{Fe}$ at once. These results suggest that it is much more difficult to strip the metal ions of interest from solutions with metal concentrations near saturation, and/or a bit "dirty" with traces of several contaminating metal ions. Amongst the other analyzed metals, only Ca summed $13.5 \mathrm{mg} \mathrm{L}^{-1}$, all the others ( $\mathrm{Al}, \mathrm{Mg}$, Ce) summed 1-2 $\mathrm{mg} \mathrm{L}^{-1}$ in all solutions. These observations may possibly confirm the selectivity of DMDCHTDGA towards $\mathrm{Pt}$ and $\mathrm{Fe}$, leaving the other contaminant metals in the raffinate.

Reutilization experiments of DMDCHTDGA were also performed. In these tests, the same portion of 0.25 M DMDCHTDGA organic phase suffered five sequential extractionscrubbing-stripping contacts. Each cycle included an extraction, a scrubbing equilibration with distilled water, and a stripping contact with $0.1 \mathrm{M}$ thiourea in $1 \mathrm{M} \mathrm{HCl}$. The data obtained for Pt and Fe is depicted in Figure 5, in which the metallic concentrations in the organic phase, in water and in thiourea solution are presented.
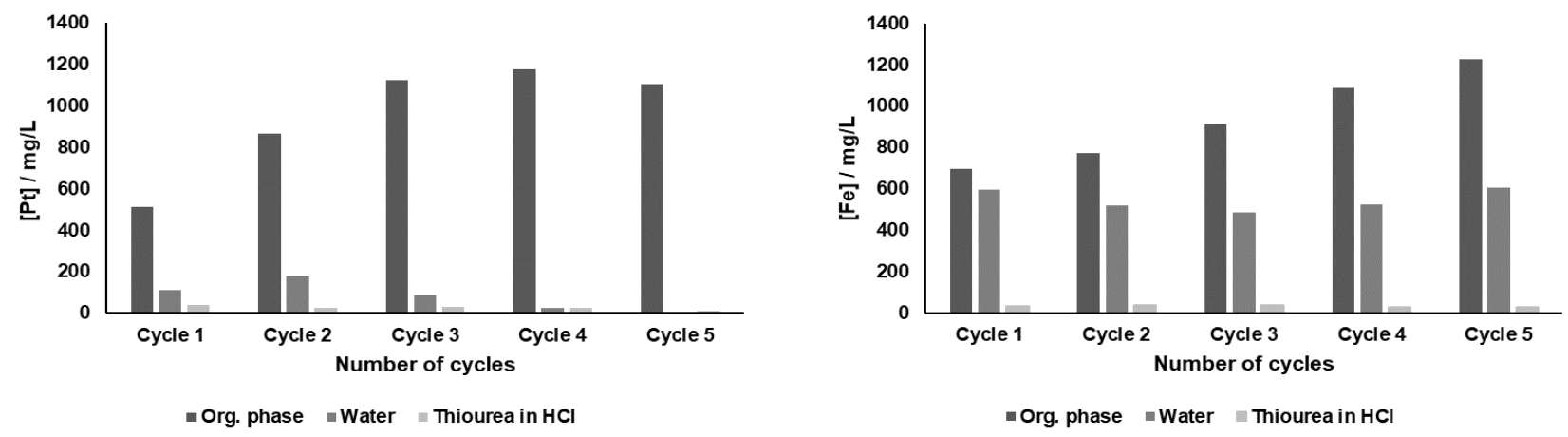

Figure 5. SX profiles shown by 0.25 M DMDCHTDGA in toluene towards Pt and Fe in the SACC leaching solution, through the metal existing concentrations in organic phase after extraction, in water (scrubbing) and in thiourea in $\mathrm{HCl}$ (stripping), during five cycles of reutilization. 
Deficient Pt removal, both by water and particularly by thiourea in $\mathrm{HCl}$, are the reasons why the recovery of $\mathrm{Pt}$ through reutilization of this $\mathrm{SX}$ system was not possible. The solvent has a very good saturation profile, and hence $\mathrm{Pt}$ was efficiently loaded until the 4th contact, being slightly released to the aqueous phase after the 5th contact. DMDCHTDGA did not reach saturation with $\mathrm{Fe}$, since it increasingly accumulated in the organic phase; water was efficient to remove Fe in the 1st cycle but lost its efficacy for the more concentrated Fe solutions. All thiourea aqueous phases presented traces of Fe.

The profiles obtained for $\mathrm{Al}, \mathrm{Ce}, \mathrm{Ca}$ and $\mathrm{Mg}$ showed that there was some accumulation for all of them in DMDCHTDGA in the first two cycles, but from the third cycle onwards the analytical data provided some erratic results, being therefore not reliable.

Data obtained with the model solution, described in Section 2.3.1, showed that thiourea could only strip half Pt from the organic phase, but these values became much more aggravated for the SACC solution, even for the 1st cycle. Water stripped $111 \mathrm{mg} \mathrm{L}^{-1}$ and $178 \mathrm{mg} \mathrm{L}^{-1} \mathrm{Pt}$ in the 1st and 2nd cycles, and this did not occur in the SX experiments with the model solution. The high complexity provided by the different metallic species, probably present in the SACC leaching solution, should be the main reason justifying the different results obtained when the model and the SACC aqueous phases are compared, although the diverse $\mathrm{HCl}$ concentrations may also play a determinant role.

To find suitable stripping agents for $\mathrm{Pt}$, the remaining loaded DMDCHTDGA organic solutions were additionally subject to additional contacts with alternative scrubbing/stripping agents, namely, $0.1 \mathrm{M} \mathrm{NH}_{4} \mathrm{Cl}$ in $1 \mathrm{M} \mathrm{NH}_{3}$ and $1 \mathrm{M} \mathrm{HCl}$ followed by $0.1 \mathrm{M}$ $\mathrm{NH}_{4} \mathrm{Cl}$ in $1 \mathrm{M} \mathrm{NH}_{3}$ [23]. During the contacts with the ammoniacal solutions, some precipitation occurred and, therefore, the mass balance to determine the metal concentrations cannot be used reliably. Even after separation of the aqueous phases some turbidity appeared, which had tendency to disappear with time. The ICP-AES results of the stripping aqueous solutions did not reveal any appreciable stripping, either for Pt or Fe. Accordingly, these alternative stripping agents for Pt should be tested with fresh DMDCHTDGA, loaded from a model solution, before their use could be extended to more complex situations.

\section{Materials and Methods}

\subsection{Sample Preparation and Characterization}

The selected SACC was ground and sieved under $1 \mathrm{~mm}$ of diameter using a cutting mill (IKA MF10, IKA-Werke GmbH \& Co., Staufen, Germany). The particle size analysis was assessed using standardized sieves.

Samples for the leaching experiments were prepared using a Jones divider to obtain two fractions of catalyst. One of them was kept for carrying out the leaching-SX experiments and the other for optimization of the leaching tests. This latter fraction (approximately $340 \mathrm{~g}$ ) was prepared using a rotating divider (Spinning Riffler Microscal, LTD, London, $\mathrm{UK})$, and 18 representative samples of approximately $20 \mathrm{~g}$ were obtained.

Wavelength dispersive X-ray fluorescence (WDXRF) analysis of SACC was performed in an ARL ADVANT'XP + sequential model from THERMO (SCAI-Malaga University, Málaga, Spain). Elemental concentration data was obtained using the UNIQUANT Integrated Software, 6th version.

\subsection{Leaching Experiments}

The preparation of four leaching solutions was made from dilution and/or dissolution of the appropriate reagents (of analytical purity) in demineralized water. $37 \%(w / w) \mathrm{HCl}$ analytical reagent grade and $30 \% \mathrm{H}_{2} \mathrm{O}_{2}$ reagent grade were used (Fisher Chemicals, Fisher Scientific Unipessoal, Lisboa, Portugal). Table 3 summarizes the composition of the leaching solutions tested in this work.

Leaching experiments were carried out in a $250 \mathrm{~mL}$ closed cylindrical glass reactor, with controlled temperature inside the reaction pulp, and provided with mechanically controlled stirring with two-blade impellers at $200 \mathrm{rpm}$. Two experimental temperatures $\left(60\right.$ and $90^{\circ} \mathrm{C}$ ) for each leaching solution were used (Table 3). The SACC samples (approx- 
imately $40 \mathrm{~g}$ ) were added to the reactor containing the leaching solution only when the selected temperature was achieved. The sample/leaching solution ratio (S/L) used in all the experiments was $1 / 2 \mathrm{~kg} / \mathrm{L}$. At 15, 30,60 and $180 \mathrm{~min}$, small volume samples of the pulp (approximately $4 \mathrm{~mL}$ ) were withdrawn from the reactor, centrifuged and analyzed to assess the evolution of $\mathrm{Pt}, \mathrm{Al}$ and Ce leaching yields with time. At the end of each test, the pulp was filtered and the solid was washed with demineralized water, dried and weighed.

Table 3. Chemical composition of the leaching solutions used in this work.

\begin{tabular}{cccc}
\hline Solution Name & {$[\mathbf{H C l}] / \mathbf{M}$} & {$\left[\mathrm{CaCl}_{\mathbf{2}}\right] / \mathbf{M}$} & {$\left[\mathbf{H}_{\mathbf{2}} \mathbf{O}_{\mathbf{2}}\right] \mathbf{v o l} \%$} \\
\hline $\mathrm{Ca} 0$ & 11.6 & - & 1 \\
$\mathrm{Ca} 2$ & 8 & 2 & 1 \\
$\mathrm{Ca} 4$ & 4 & 4 & 1 \\
$\mathrm{D} 0$ & 4 & - & 1 \\
\hline
\end{tabular}

The leaching yields were determined considering the metal contents in the leaching solutions referring to their initial concentration in the SACC, obtained by WDXRF. The resulting solutions from the leaching experiments were analyzed by inductively coupled plasmaatomic emission spectrometry (ICP-AES, Horiba Jobin-Yvon S. A. S., Longjumeau, France, Ultima model). Typical errors affecting the leaching yields were in the range $\pm 3-5 \%$, considering the results achieved for replicates carried out for some experiments.

\subsection{Liquid-Liquid Extraction Experiments}

A model feed aqueous phase containing $500 \mathrm{mg} \mathrm{L}^{-1} \mathrm{Pt}(\mathrm{IV}), 1000 \mathrm{mg} \mathrm{L}^{-1} \mathrm{Al}(\mathrm{III})$, $4000 \mathrm{mg} \mathrm{L}^{-1} \mathrm{Ce}(\mathrm{III})$ and $1000 \mathrm{mg} \mathrm{L}^{-1} \mathrm{Fe}(\mathrm{III})$ in $6 \mathrm{M} \mathrm{HCl}$ was prepared from the following precursor compounds: Cerium(III) chloride heptahydrate $>98.5 \%$ purity (Fluka, a subsidiary company of Sigma-Aldrich, St. Louis, MO, USA); Ferric chloride $>98 \%$ purity (Laboratory BDH reagents, London, UK); Aluminum chloride hexahydrate 99\% Reagent plus (Sigma-Aldrich); Atomic absorption spectroscopy standards $1000 \mathrm{mg} \mathrm{L}^{-1} \mathrm{Pt}(\mathrm{IV})$ in $5 \% \mathrm{HCl}$ (Fluka). Stripping phases were arranged using the following reagents: Thiourea (99\%, Sigma-Aldrich); $\mathrm{NH}_{4} \mathrm{Cl}$ (99\%, Sigma-Aldrich); $\mathrm{NH}_{3}$ (25\% Panreac Química S. L. U., Barcelona, Spain, Reagent USP, PA); $\mathrm{HCl}$ (37\%, Fisher chemicals).

For the preparation of larger volumes of the real solutions for the SX experiments, $170 \mathrm{~g}$ of SACC were mixed with $340 \mathrm{~mL}$ of the optimized leaching solution $(11.6 \mathrm{M} \mathrm{HCl}$ with $1 \%$ vol $\left.\mathrm{H}_{2} \mathrm{O}_{2}\right)$. The resulting leaching solution was filtered $(235 \mathrm{~mL})$ and diluted with distilled water $(117 \mathrm{~mL})$.

The synthesis of $N, N^{\prime}$-dimethyl- $N, N^{\prime}$-dicyclohexylthiodiglycolamide (DMDCHTDGA) was carried out as previously described [23], the obtained characterization results being identical to those reported before. $0.25 \mathrm{M}$ solutions of DMDCHTDGA in toluene were considered for the several SX experiments.

The general extraction, stripping and scrubbing experiments adopted for the tests with model and real SACC leaching solutions were carried out by magnetically stirring equal volumes of aqueous and organic phases $(\mathrm{A} / \mathrm{O}=1)$ in stoppered Erlenmeyer flasks for $30 \mathrm{~min}[22,23]$, at room temperature, and with a rotation speed between 700-800 rpm. After separation of the two phases, the aqueous solutions were filtered using filter paper (Filtres Fioroni $\mathrm{n}^{\circ} 2$, Ingré, France), to remove any traces of organic phase. The determination of the metal concentrations in the aqueous solutions, before and after extraction, was accomplished by ICP-AES (Horiba Jobin-Yvon, Ultima), the metal ion concentrations in the organic phases being calculated by mass balance. The analysis of the aqueous solutions was thoroughly made in triplicate, and the coefficient of variation for the extraction and stripping results was about $\pm 5 \%$.

Aliquots of 30-40 mL of the diluted SACC aqueous feed leaching solution mentioned above were successively equilibrated with the same volume of $0.25 \mathrm{M}$ DMDCHTDGA in toluene to construct equilibrium extraction isotherms for $\mathrm{Pt}$ and $\mathrm{Fe}$, and to determine the maximum metal loading saturation paths. Data for the extraction isotherms were obtained 
using the same portion of organic phase, which was successively contacted with fresh aliquots of the feed SACC leaching solution by five times $(\mathrm{A} / \mathrm{O}=1)$, adopting the set of experimental conditions reported above. A small portion of each aqueous phase was collected for ICP-AES analysis, and the associated volumes of organic and aqueous phases were adjusted, to cope with the $\mathrm{A} / \mathrm{O}=1$ ratio, in the successive equilibration experiments. Concentrations in organic solutions were calculated by mass balance.

Final metal loaded organic phases were divided in smaller volumes and those were tentatively scrubbed/stripped by 1) $0.1 \mathrm{M} \mathrm{NH}_{4} \mathrm{Cl}$ in $1 \mathrm{M} \mathrm{NH}_{3}$ followed by $\mathrm{H}_{2} \mathrm{O}$ 2) $\mathrm{HCl}$ followed by $0.1 \mathrm{M} \mathrm{NH}_{4} \mathrm{Cl}$ in $1 \mathrm{M} \mathrm{NH}_{3}$, and $\mathrm{H}_{2} \mathrm{O}$ 3) $0.1 \mathrm{M}$ thiourea in $1 \mathrm{M} \mathrm{HCl}$.

Reutilization experiments for DMDCHTDGA organic phases were additionally carried out involving the diluted SACC aqueous feed leaching solution. In these tests, the same portion of organic phase suffered five sequential extraction-scrubbing-stripping contacts with $\mathrm{A} / \mathrm{O}=1$ for 30 min at room temperature, and with a rotation speed between 700-800 rpm. Each cycle included an extraction, a scrubbing equilibration with distilled water, and a stripping contact with $0.1 \mathrm{M}$ thiourea in $1 \mathrm{M} \mathrm{HCl}$. After separation of phases, the aqueous solutions were filtered using filter paper (Filtres Fioroni $\mathrm{n}^{\circ} 2$ ) and analyzed for the most abundant metals, e.g., Pt, Fe, Ce, Mg, Ca, and Al. The adopted methodology was like the one reported above for the saturation experiments: A small portion of each aqueous phase was collected for ICP-AES analysis, and the associated volumes of organic and aqueous phases were adjusted, to cope with the $\mathrm{A} / \mathrm{O}=1$ ratio, in the successive equilibration experiments. Concentrations in the organic solutions were calculated by mass balance.

The resulting recycled organic phase was divided in smaller volumes and those were tentatively scrubbed/stripped by: (1) $\mathrm{H}_{2} \mathrm{O}$ (2) $\mathrm{H}_{2} \mathrm{O}$ followed by $0.1 \mathrm{M}$ thiourea in $1 \mathrm{M} \mathrm{HCl}$, (3) $1 \mathrm{M} \mathrm{HCl}$ followed by $0.1 \mathrm{M}$ thiourea in $1 \mathrm{M} \mathrm{HCl}$ (4) $0.1 \mathrm{M} \mathrm{NH}_{4} \mathrm{Cl}$ in $1 \mathrm{M} \mathrm{NH}_{3}$ (5) $1 \mathrm{M}$ $\mathrm{HCl}$ followed by $0.1 \mathrm{M} \mathrm{NH}_{4} \mathrm{Cl}$ in $1 \mathrm{M} \mathrm{NH}_{3}$.

\section{Conclusions}

The highest yield of Pt leaching (above 80\%) from the selected vehicle catalyst, together with a lower $\mathrm{Al}$ leaching, was achieved by treating the catalyst under the following conditions: $11.6 \mathrm{M} \mathrm{HCl}$ leaching solution with $1 \%$ vol of $\mathrm{H}_{2} \mathrm{O}_{2}$ during $1 \mathrm{~h}$ at $60{ }^{\circ} \mathrm{C}$.

Chloride ions in the $\mathrm{HCl}$ solution replaced by salts like $\mathrm{CaCl}_{2}$ would allow the decrease of the acid content in the leaching phase, and this hypothesis was tested herein. The bestfound acid/salt combination was $8 \mathrm{M} \mathrm{HCl} / 2 \mathrm{M} \mathrm{CaCl}_{2}$ (and with identical remaining conditions), and it gave comparable results to the most acidic leaching phases. Another interesting leaching feature adopted in this work was the use of very high pulp densities $(\mathrm{S} / \mathrm{L}=1 / 2 \mathrm{~kg} / \mathrm{L})$, and therefore concentrated Pt solutions were obtained, with about $1 \mathrm{~g} / \mathrm{L}$ Pt. The main contaminant element, aluminum, was present in the leachate at concentrations around $5 \mathrm{~g} / \mathrm{L}$, which can be judged a relatively low value considering the high content of this metal in the catalyst.

SX with DMDCHTDGA to recover Pt from a real SACC solution has been a pioneering development in this work. Results achieved with a model solution were firstly accessed, anticipating a better SX performance for the real SACC solution, which did not happen. For the adopted experimental conditions, DMDCHTDGA revealed a very good loading performance for both $\mathrm{Pt}$ and $\mathrm{Fe}$, but the stripping agents used for the metal recoveries did not work properly, thus not allowing the efficient reutilization of the organic solvent. Additional efforts are being developed to check the viability of using ammoniacal solutions for a better Pt stripping from DMDCHTDGA.

Author Contributions: Experimental work, A.M.; conceptualization, A.M., C.A.N., A.P.P.; writingreview and editing, A.M., C.A.N., A.P.P. All authors have read and agreed to the published version of the manuscript. 
Funding: This research was funded by FUNDAÇÃO PARA A CIÊNCIA E A TECNOLOGIA, project number UIDB/00100/2020; and MINISTERIO DE EDUCACION, CULTURA y DEPORTE, program SALVADOR DE MADARIAGA 2017 PRX17/00286.

Institutional Review Board Statement: Not applicable.

Informed Consent Statement: Not applicable.

Data Availability Statement: Not applicable.

Conflicts of Interest: The authors declare no conflict of interest. The funders had no role in the design of the study; in the collection, analyses, or interpretation of data; in the writing of the manuscript, or in the decision to publish the results.

\section{References}

1. European Commission. Report on Critical Raw Materials for the EU. European Commissions, Brussels. 2011. Available online: https:/ / eur-lex.europa.eu/legal-content/EN/TXT/PDF/?uri=CELEX:52011DC0025\&from=EN (accessed on 22 January 2021).

2. European Commission. Report on Critical Raw Materials for the EU. European Commissions, Brussels. 2014. Available online: https:/ / eur-lex.europa.eu/legal-content/EN/TXT/PDF/?uri=CELEX:52014DC0297\&from=EN (accessed on 22 January 2021).

3. European Commission. Report on Critical Raw Materials for the EU. European Commissions, Brussels. 2017. Available online: https:/ / eur-lex.europa.eu/legal-content/EN/TXT/PDF/?uri=CELEX:52017DC0490\&from=EN (accessed on 22 January 2021).

4. European Commission. Report on Critical Raw Materials for the EU. European Commissions, Brussels. 2020. Available online: https:/ / eur-lex.europa.eu/legal-content/EN/TXT/PDF/?uri=CELEX:52020DC0474\&from=EN (accessed on 22 January 2021).

5. Cabri, L.J. Platinum-Group Elements: Mineralogy, Geology, Recovery; The Canadian Institute of Mining and Metallurgy: Montreal, QC, Canada, 1981.

6. Mpinga, C.N.; Eksteen, J.J.; Aldrich, C.; Dyer, L. Direct leach approaches to platinum group metal (PM) ores and concentrates: A review. Miner. Eng. 2015, 78, 93-113. [CrossRef]

7. Charlesworth, P. Separating the platinum group metals by liquid-liquid extraction. New process has potential economic advantages over conventional selective precipitation. Platin. Met. Rev. 1981, 25, 106-112.

8. Cooper, W.C. The treatment of copper refinery anode slimes. JOM 1990, 42, 45-49. [CrossRef]

9. Ferron, C.J. Chapter 46: Recovery of gold as by-product from the base-metals industries. In Gold Ore Processing; Adams, M.D., Ed.; Elsevier: Amsterdam, The Netherlands, 2016.

10. Dong, H.; Zhao, J.; Chen, J.; Wu, Y.; Li, B. Recovery of platinum group metals from spent catalysts: A review. Int. J. Miner. Process. 2015, 145, 108-113. [CrossRef]

11. Yang, C.J. An impending platinum crisis and its applications for the future of the automobile. Energy Policy 2009, 37, 1805-1808. [CrossRef]

12. Hou, J.; Yang, M.; Ke, C.; Wei, G.; Priest, C.; Qiao, Z.; Wu, G.; Zhang, J. Platinum-group-metal catalysts for proton exchange membrane fuel cells: From catalyst design to electrode structure optimization. EnergyChem 2020, 2, 100023. [CrossRef]

13. Fornalczyk, A. Industrial catalysts as a source of valuable metals. J. Achiev. Mater. Manuf. Eng. 2012, 55, 864-869.

14. Peng, Z.; Li, Z.; Lin, X.; Tang, H.; Ye, L.; Ma, Y.; Rao, M.; Zhang, Y.; Li, G.; Jiang, T. Pyrometallurgical recovery of platinum group metals from spent catalysts. JOM 2017, 69, 1553-1562. [CrossRef]

15. Steinlechner, S.; Antrekowithsch, J. Potential of a hydrometallurgical recycling process for catalyst to cover the demand for critical metals, like PGMs and cerium. JOM 2015, 67, 406-411. [CrossRef]

16. Saguru, C.; Ndlovu, S.; Moropeng, D. A review of recent studies into hydrometallurgical methods for recovering PGMs from used catalytic converters. Hydrometallurgy 2018, 182, 44-56. [CrossRef]

17. Jha, M.K.; Lee, J.C.; Kim, M.S.; Jeong, J.; Kim, B.S.; Kumar, V. Hydrometallurgical recovery/recycling of platinum by the leaching of spent catalysts: A review. Hydrometallurgy 2013, 133, 23-32. [CrossRef]

18. Harjanto, S.; Cao, Y.; Shibayama, A.; Naitoh, I.; Nanami, T.; Kasahara, K.; Okumura, Y.; Liu, K.; Fujita, T. Leaching of Pt, Pd and Rh from automotive catalyst residue in various chloride based solutions. Mater. Trans. 2006, 47, 129-135. [CrossRef]

19. Nogueira, C.A.; Paiva, A.P.; Oliveira, P.C.; Costa, M.C.; Rosa da Costa, A.M. Oxidative leaching process with cupric ion in hydrochloric acid media for recovery of Pd and Rh from spent catalytic converters. J. Hazard. Mater. 2014, 278, 82-90. [CrossRef]

20. Paiva, A.P.; Ortet, O.; Carvalho, G.I.; Nogueira, C.A. Recovery of palladium from a spent industrial catalyst through leaching and solvent extraction. Hydrometallurgy 2017, 171, 394-401. [CrossRef]

21. Costa, M.C.; Assunção, A.; Almeida, R.; Rosa da Costa, A.M.; Nogueira, C.; Paiva, A.P. $N, N^{\prime}$-dimethyl- $N$, $N^{\prime}$-dicyclohexylsuccinamide: A novel molecule for the separation and recovery of $\mathrm{Pd}(\mathrm{II})$ by liquid-liquid extraction. Sep. Purif. Technol. 2018, 201, 96-105. [CrossRef]

22. Ortet, O.; Paiva, A.P. Liquid-liquid extraction of palladium(II) from chloride media by $N, N^{\prime}$-dimethyl- $N, N^{\prime}$-dicyclohexylthiodiglycolamide. Sep. Purif. Technol. 2015, 156, 363-368. [CrossRef]

23. Paiva, A.P.; Carvalho, G.I.; Costa, M.C.; Rosa da Costa, A.M.; Nogueira, C.A. Recovery of platinum and palladium from chloride solutions by a thiodiglycolamide derivative. Solvent Extr. Ion Exch. 2014, 32, 78-94. [CrossRef]

24. Costa, M.C.; Almeida, R.; Assunção, A.; Rosa da Costa, A.M.; Nogueira, C.; Paiva, A.P. N,N'-tetrasubstituted succinamides as new molecules for liquid-liquid extraction of Pt(IV) from chloride media. Sep. Purif. Technol. 2016, 158, 409-416. [CrossRef] 
25. Rzelewska-Piekut, M.; Paukszta, D.; Regel-Rosocka, M. Hydrometallurgical recovery of platinum group metals from spent automotive converters. Physicochem. Probl. Miner. Process. 2021, 57, 83-94. [CrossRef]

26. Ortet, O.; Santos, M.S.C.S.; Paiva, A.P. Palladium(II) and $N, N^{\prime}$-dimethyl- $N, N^{\prime}$-dicyclohexylthiodiglycolamide-The extracted species from concentrated chloride solutions. Sep. Purif. Technol. 2016, 170, 1-9. [CrossRef]

27. Aberasturi, D.J.D.; Pinedo, R.; Larramendi, I.R.D.; Larramendi, J.I.R.D.; Rojo, T. Recovery by hydrometallurgical extraction of the platinum-group metals from car catalytic converters. Miner. Eng. 2011, 24, 505-513. [CrossRef]

28. Palacios, M.A.; Gómez, M.M.; Moldovan, M.; Morrison, G.; Rauch, S.; McLeod, C.; Ma, R.; Laserna, J.; Lucea, P.; Caroli, S.; et al. Platinum-group elements: Quantification in collected exhaust fumes and studies of catalyst surfaces. Sci. Total Environ. 2000, 257, 1-15. [CrossRef]

29. Zhao, Z.; Qiu, Z.; Yang, J.; Ma, B.; Li, Z.; Lu, S.; Xu, Y.; Cao, L.; Zhang, W. Recovery of rare earth element cerium from spent automotive exhaust catalysts using a novel method. Waste Biomass Valorization 2020, 11, 4967-4976. [CrossRef]

30. Ge, Y.; Fu, K.; Zhao, Q.; Ji, N.; Song, C.; Ma, D.; Liu, Q. Performance study of modified Pt catalysts for the complete oxidation of acetone. Chem. Eng. J. 2019, 206, 499-506. [CrossRef]

31. Yentekakis, I.V.; Vernoux, P.; Goula, G.; Caravaca, A. Electropositive promotion by alkalis or alkaline earths of Pt-group metals in emissions control catalysis: A status report. Catalysts 2019, 9, 157. [CrossRef]

32. Angelidis, T.N.; Skouraki, E. Preliminary studies of platinum dissolution from a spent industrial catalyst. Appl. Catal. A Gen. 1996, 142, 387-395. [CrossRef]

33. Lakshamanan, V.I.; Sridhar, R.; Chen, J.; Halim, M.A. Development of mixed chloride hydrometallurgical processes. Trans. Indian Inst. Met. 2016, 69, 39-50. [CrossRef] 